Original Research Paper

\title{
Skrining Kelainan Mata Pada Siswa Sdit Abata Mataram
}

\author{
Ni Nyoman Geriputri ${ }^{1 *}$, Ika Primayanti ${ }^{1}$, Eva Triani $^{1}$, Rika Hastuti Setyorini ${ }^{1}$, Ida \\ Lestari Harahap ${ }^{1}$
}

${ }^{1}$ Fakultas Kedokteran, Universitas Mataram

*Corresponding Author: Ni Nyoman Geriputri, Fakultas Kedokteran, Universitas Mataram, Indonesia;

Email: geriputri@yahoo.com

\begin{abstract}
Abstrak: Mata sebagai panca indera penting memerlukan pemeriksaan dan perawatan teratur. Pemeriksaan rutin sebaiknya dilakukan sejak usia dini untuk mendeteksi adanya kelainan refraksi dan kondisi mata lainnya yang dapat mengarah pada gangguan penglihatan permanen. Anak-anak usia sekolah terpapar pada sekumpulan penyakit dan kelainan mata yang sebagian berpotensi menimbulkan gangguan penglihatan permanen baik pada masa kanak-kanak maupun masa kehidupan selanjutnya. Kelainan refraksi dan kondisi mata lainnya berpotensi mempengaruhi kemampuan siswa untuk belajar atau mengganggu performa akademisnya. Penglihatan yang buruk tidak hanya menghalangi kegiatan belajar di sekolah tetapi juga berpengaruh pada masa dewasa nantinya karena $80 \%$ proses belajar anak-anak diperoleh melalui sistem visual. Sebagian besar kondisi ini dapat dicegah atau diobati bila ditemukan lebih awal. Kelainan mata pada anak seringkali sulit untuk ditemui karena berbagai faktor, baik dari internal anak maupun faktor eksternal, yaitu dari guru dan orang tua. Kurangnya pengetahuan mengenai tanda dan gejala kelainan mata menjadi penyebab terlambatnya penanganan gangguan penglihatan yang dapat dicegah. Deteksi kelainan mata pada siswa SDIT Abata Mataram dapat dilakukan melalui skrining secara berkala. Berdasar hasil kegiatan skrining yang dilakukan pada siswa SDIT Abata Mataram didapatkan 15\% dari 26 siswa mengalami kelainan yang dicurigai sebagai gangguan refraksi, tanpa adanya kelainan lain pada mata. Dianjurkan kepada guru agar menyampaikan hasil pemeriksaan kepada orang tua/wali murid untuk selanjutnya memeriksakan putra/putrinya yang memiliki kelainan refraksi ke dokter spesialis mata.
\end{abstract}

Kata Kunci: Skrining, Kelainan Mata

\section{Pendahuluan}

Mata adalah salah satu dari panca indera penting yang memerlukan pemeriksaan dan perawatan secara teratur. Pemeriksaan rutin pada mata sebaiknya dimulai sejak usia dini. Skrining mata bahkan perlu dimulai sejak bayi baru lahir untuk mendeteksi adanya kelainan pada mata, sementara untuk menilai tajam penglihatan dimulai sejak usia 3 tahun. American Academy of Pediatrics merekomendasikan skrining neonatus harus dilakukan sebelum usia 3 bulan dan intervensi telah diberikan sebelum usia 6 bulan. Untuk bayi yang lulus skrining, tetap harus dilakukan evaluasi berkala, yakni pada usia 6 bulan-1 tahun, usia 3-4 tahun, usia sekolah, ataupun setiap saat bila ada kecurigaan gangguan penglihatan. Pada usia bayi, evaluasi penglihatan adalah dengan pemeriksaan red reflex, kedudukan dan pergerakan bola mata. Di atas usia tiga tahun, penilaian tajam penglihatan menggunakan chart huruf, angka, atau gambar tertentu sudah dapat dilakukan (AAP, 2016).

Anak usia sekolah di seluruh dunia terpapar oleh sekumpulan penyakit dan kondisi mata, yang sebagian dapat mengarah ke gangguan penglihatan permanen pada masa kanak-kanak atau pada masa selanjutnya. Sebagian besar dari kondisi ini dapat dicegah atau diobati bila terdiagnosis lebih awal. Gangguan penglihatan memiliki konsekuensi yang 
serius untuk kehidupan anak-anak bila tidak diatasi. Penglihatan yang buruk tidak hanya menghalangi kegiatan belajar di sekolah tetapi juga berpengaruh pada masa dewasa nantinya karena $80 \%$ proses belajar anak-anak diperoleh melalui sistem visual. Sekitar 1,4 juta anak-anak di dunia mengalami kebutaan irreversibel selama hidupnya dan prevalensi kebutaan pada anak-anak bisa mencapai 1,5 per 1000 anak (WHO, 2017).

World Health Organization membagi penyebab kebutaan pada anak menjadi dua kelompok besar, yaitu berdasar anatomi dan etiologi (asal mula). Secara anatomi dapat berupa kelainan pada bola mata, katarak, glaukoma, kelainan refraksi, atau ambliopia/mata malas. Bila dilihat dari etiologi dapat berupa kelainan genetik, gangguan retina akibat kelahiran prematur, atau akibat kekurangan asupan vitamin (ICOPH, 2011).

Tujuan dari skrining penglihatan pada anakanak usia sekolah adalah untuk mendeteksi kelainan refraksi dan kondisi mata lainnya yang berpotensi mempengaruhi kemampuan siswa untuk belajar atau mengganggu performa akademisnya. Skrining penglihatan merupakan suatu metode yang efektif biaya untuk mengidentifikasi anak-anak yang memerlukan evaluasi dan penanganan oleh dokter mata. Diagnosis dan penanganan gangguan penglihatan di awal akan memberikan kesempatan untuk perkembangan visual yang normal, mencegah hilangnya tajam penglihatan lebih lanjut, serta dapat menurunkan masalah akibat gangguan belajar, performa sekolah yang rendah, gangguan tumbuh kembang dan masalah terkait tingkah laku (Prevent Blindness, 2018).

Kelainan mata pada anak seringkali sulit ditemui akibat dari beberapa faktor. Anak-anak umumnya tidak mengeluhkan gangguan yang mereka alami karena tidak mengetahui bahwa ternyata mata mereka bermasalah. Penyebab lain adalah adanya rasa takut untuk menyampaikan keluhan kepada orang tua ataupun rasa takut untuk periksa ke dokter. Selain itu kurangnya pengetahuan guru dan orang tua akan tanda dan gejala gangguan tajam penglihatan dan kondisi mata lain, dapat menjadi penyebab dari keterlambatan diagnosis dan penanganan kebutaan yang dapat dicegah. Deteksi kelainan mata pada siswa SDIT Abata Mataram melalui pemeriksaan tajam penglihatan dan pemeriksaan dasar mata oleh dokter yang berasal dari Fakultas Kedokteran Universitas Mataram.

\section{Metode Pelaksanaan}

Tujuan kegiatan ini adalah untuk mengetahui kondisi kesehatan mata siswa SD sebagai salah satu bentuk deteksi dini adanya kelainan mata yang dapat menimbulkan gangguan penglihatan melalui pemeriksaan rutin (skrining). Manfaat yang dapat diperoleh dari kegiatan ini adalah mendapatkan data tentang kelainan mata pada siswa SD.

Kegiatan ini dapat menjadi kegiatan awal dari kegiatan promotif dan preventif mengenai deteksi dini kelainan mata pada siswa SDIT Abata Mataram dan memberikan kesadaran kepada orangtua mengenai pentingnya melakukan pemeriksaan kesehatan mata siswa sebagai upaya promotif dan preventif. Kegiatan dilaksanakan dengan cara: 1) menawarkan kegiatan pemeriksaan kesehatan mata secara rutin dan berkala dan memberikan edukasi dan konsultasi lanjutan dengan melibatkan dokter ahli di bidangnya dengan mekanisme rujukan. Pelaksanaan kegiatan ini dilaksanakan pada bulan September 2018 pada siswa SDIT Abata Mataram.

\section{Hasil dan Pembahasan}

Kegiatan skrining kelainan mata pada siswa SDIT Abata Mataram yang beralamat di Jl. Adi Sucipto XX, Mataram berlangsung pada 27 September dan 4 Oktober 2018. Pemeriksaan dilakukan pada siswa kelas II-V yang berjumlah 26 siswa dan 4 orang guru, sehingga total 30 orang. Pemeriksaan mata yang dilakukan meliputi pemeriksaan tajam penglihatan, mata bagian luar, media refraksi, dan mata bagian dalam. Alat pemeriksaan yang digunakan antara lain: kartu Snellen, gagang coba, pinhole, senter, lup, dan oftalmoskop direk.

Berdasar kegiatan skrining didapatkan 4 siswa dari total 26 siswa mengalami gangguan tajam penglihatan atau gangguan refraksi. Gangguan refraksi adalah ketidakmampuan mata untuk melihat fokus pada objek yang berada pada jarak tertentu dari mata. Kelainan refraksi terbagi menjadi miopia (rabun jauh), hipermetropia (rabun jauh dan dekat), dan astigmatisme. Sekitar 10\% dari 66 juta anak usia sekolah (5-19 tahun) 
menderita gangguan refraksi, dengan miopia sebagai kelainan refraksi terbanyak. Hingga saat ini angka pemakaian kaca mata koreksi masih sangat rendah.

Gangguan refraksi dapat disebabkan oleh beberapa faktor risiko seperti faktor genetik dan faktor lingkungan. Riwayat penggunaan kaca mata pada orang tua ataupun saudara kandung menjadi faktor predisposisi terjadinya miopia. Faktor lingkungan yang saat ini harus menjadi perhatian adalah meningkatnya penggunaan alat canggih/gawai pada anak-anak. Penemuan kasus dengan lebih cepat memungkinkan penanganan lebih segera sehingga kualitas penglihatan baik dan diharapkan prestasi belajar meningkat.

\section{Kesimpulan}

Berdasarkan pada hasil dan proses pelaksanaan kegiata pengabdian ini, dapat disimpulkan anak usia sekolah merupakan populasi yang rentan mengalami gangguan refraksi. Pada kegiatan skrining ini didapatkan $15 \%$ siswa mengalami gangguan tajam penglihatan yang dicurigai sebagai gangguan refraksi. Semua kelainan ini ditemukan pada siswa yang tidak mengeluhkan adanya gangguan pada penglihatan mereka.

Gangguan penglihatan akibat kelainan refraksi menjadi masalah yang harus segera ditangani karena dapat mengakibatkan kebutaan bila diabaikan.

\section{Saran}

Berdasar hasil kegiatan ini, direkomendasikan kepada orang tua/wali murid untuk memeriksakan lebih lanjut putra/putrinya ke dokter spesialis mata untuk memastikan jenis kelainan refraksi yang dialami.

\section{Daftar Pustaka}

American Academy of Pediatrics, 2003. Eye Examination in Infants, Children, and Young Adults by Pediatricians. Pediatrics. 111: 902-907.
Lansingh, Van C, 2011. Childhood Blindness: Public Health Presentation. Tersedia pada laman www.icoph.org/resources/260/ChildhoodBlindness--Public-Health-

Presentation.html (diakses pada 25 Maret 2018).

Prevent Blindness, 2018. Prevent Blindness Position Statement: Children's Vision and Eye Health. Tersedia pada laman https://www.preventblindness.org/childre ns-vision-and-eye-health (diakses pada 25 Maret 2018).

World Health Organisation, 2017. Visual Impairment And Blindness - Fact Sheet No. 282. Tersedia pada laman http://www.who.int/mediacentre/factsheet s/fs282/en/ (diakses pada 25 Maret 2018). 